\title{
Arabic Ethnic Houses In Kampung Arab Pasar Kliwon As The Product Of Acculturation
}

\author{
Rumah Tua Etnik Arab Di Kampung Arab \\ Pasar Kliwon Sebagai Hasil AkUlturasi
}

\author{
Najmi Muhamad Bazher ${ }^{*}$ \\ MENARA, Study and Research Center of Arab Ancestry in Indonesia \\ Email : bazhernajmi@gmail.com*
}

\begin{abstract}
The wave of migration to Indonesia cause multiculturalism in their communities. Acculturation happened when the imigrant's culture meet and blend with the native's culture. Hadhrami immigrants came and stayed in Indonesia, bringing their original culture from Yaman. Islam as their religion became the important part of their life and effecting the culture, wherever they live. Adapting to the native culture and local condition was needed when they chose to settle in Indonesia. Dutch colonization at that time effected Indonesian society's way of life, so are the immigrants. Socio-cultural dynamics will influence and expressed by architecture form. The objective of this study was to identify acculturation between Arab, Islam, Indonesia, and Dutch culture on architecture of Arab's antique houses in Kampung Arab Pasar Kliwon. Research method used in this study is qualitative-explorative and using descriptive as analysis method. Acculturation between Arab, Islam, Indonesia, and Dutch cultures on the Arab's antique houses in Kampung Arab Pasar Kliwon, found through the existence of Arab vernacular architecture, islamic concept architecture, tropical-humid architecture, and Dutch colonial architecture on the design program, interior elements, and exterior elements.
\end{abstract}

Keywords: acculturation, Arab-Indonesian, antique house, kampung Arab, Pasar Kliwon.

\section{PENDAHULUAN}

Sejak dulu, Indonesia memiliki kontak dagang dengan bangsa asing, khususnya India, Arab, Cina, dan Eropa (Usman, 2009). Gelombang migrasi dari luar negeri ke nusantara menyebabkan keberagaman budaya (multikulturalisme) (Ashworth dkk, 2007). Imigran berkebudayaan tertentu tersebut mengalami kontak sosial dengan kebudayaan asing di tempat baru, hingga terjadi penyesuaian budaya yang disebut akulturasi (Koentjaraningrat, 1985).

Berbeda dengan warga timur asing lainnya, yaitu Cina dan India yang relatif terpisah dengan kaum pribumi, imigran Arab (mayoritas dari Hadhramaut, Yaman) sejak semula menyatu dengan pribumi (Kesheh, 2007). Hal ini dikarenakan adanya persamaan kepercayaan yaitu agama Islam (Kesheh, 2007). Imigran
Arab tersebut tidak hanya datang ke Indonesia untuk berdagang, namun juga untuk menyebar-kan agama. Ajaran dari agama tersebut mem-bentuk kebudayaan Islam yang melebur dengan kebudayaan Arab yang dibawa oleh kaum Hadhrami (warga dari Hadhramaut). Persama-an agama juga mendorong terjadinya perkawi-nan antara imigran Hadhrami dengan wanita pribumi (Kesheh, 2007) hingga terjadi pen-campuran budaya Arab dengan Indonesia. Hal lain yang menyebabkan persatuan antara kaum Hadhrami dengan pribumi adalah perju-angan melawan penjajahan dari Belanda (Ke-sheh, 2007). Keberadaan penjajah Belanda memberikan pengaruh pada pola hidup masyarakat di Indonesia seperti dalam hal bermukim. Pihak koloni menerapkan politik wijkenstelsel 
atau passen stelsel dibuat untuk mengisolasi warga timur asing (termasuk Hadhrami) dari pribumi melalui penempatan pada kawasan tersendiri (Kesheh, 2007). Kawasan tempat di mana orang Arab tersebut tinggal selanjutnya dikenal sebagai kampung Arab. Menurut F. Christian (1992), dinamika sosial-budaya akan sangat mempengaruhi dinamika arsitektur. Sehingga proses akukturasi yang ter-jadi dapat diidentifikasi melalui obyek arsitek-tur. Arsitektur rumah di Jazirah Arab sebagai hasil budaya Arab, arsitektur rumah islami yang mewujudkan konsep ajaran Agama Islam, arsitektur bangunan kolonial dengan pengaruh Belanda, dan arsitektur tropis dengan pengaruh budaya serta konteks tropis Indonesia yang masing-masing memiliki karakter.

Solo merupakan salah satu kota tua di Indonesia yang menyimpan berbagai peninggalan kebudayaan dari bermacam etnik (Himawan, 2001). Oleh karena itu, Solo dirasa tepat digunakan sebagai lokasi penelitian untuk melacak sejarah akulturasi etnis Arab. Etnis Arab di Solo bermukim di Kampung Arab Pasar Kliwon. Obyek arsitektur sebagai obyek penelitian yang dipilih adalah bangunan berumur di atas 50 tahun (sesuai kriteria konservasi) yang be-lum terkena arus globalisasi, sehingga akar bu-dayanya masih dapat terlacak. Elemen fisik yang signifikan membentuk suasana atau sense of place Kampung Arab Pasar Kliwon adalah rumah tua milik etnis Arab (Bazher dkk, 2017). Bangunan tersebut dipilih sebagai obyek studi karena sesuai dengan kriteria obyek penelitian. Menurut Amos Rapoport (1981), arsitektur adalah ruang tempat hidup manusia yang lebih dari sekedar fisik, tapi juga menyangkut pranata-pranata budaya dasar. Dikatakan oleh Clyde Kluckhohn (1953) bahwa arsitektur tergolong peralatan dan perlengkapan hidup manusia yang termasuk dalam tujuh unsur kebudayaan universal. Kebudayan seseorang dapat terlihat pada arsitektur rumah tinggalnya. Dalam kasus ini, rumusan masalahnya adalah sejauhmana peleburan kebudayaan Arab, Islam, Indonesia, dan Belanda pada arsitektur rumah tua etnis Arab di Kampung Arab Pasar Kliwon?

Tujuan penelitian ini adalah mengkaji hubungan antara budaya dengan elemen arsitektur dan mengidentifikasikan peleburan antara kebudayaan Arab, Islam, Indonesia, dan Belanda pada arsitektur rumah tua etnis Arab di Kampung Arab Pasar Kliwon, Surakarta. Untuk mencapai tujuan tersebut, maka sasaran dalam penelitian ini adalah mengidentifikasi elemen arsitektur Arab (khususnya Yaman), arsitektur Islam, arsitektur tropis Indonesia, dan arsitektur kolonial Belanda di Indonesia pada pola ruang, interior, dan eksterior rumah tua etnis Arab di Kampung Arab Pasar Kliwon, Surakarta. Menurut E. B. Tylor, kebudayaan adalah kom-pleks yang mencakup pengetahuan, kepercaya-an, moral, hukum, kesenian, adat, dan kebiasaan yang didapatkan oleh manusia sebagai anggota dari masyarakat. Fenomena yang timbul seba-gai hasil, jika kelompok-kelompok manusia dengan kebudayaan yang berbeda bertemu dan mengadakan kontak secara langsung dan terusmenerus, yang kemudian menimbulkan peruba-han dalam pola kebudayaan yang original dari salah satu kelompok atau pada keduanya, dise-but akulturasi (Harsojo, 1984). Proses akultura-si diawali dengan fase akomodasi yaitu saat suatu kelompok dengan kelompok lain saling berkompromi/bersepakat terhadap suatu hal sehingga menimbulkan perdamaian (Koentara-ningrat, 1985). Fase selanjutnya adalah asimi-lasi yaitu suatu proses sosial yang telah lanjut (berlangsung lama), ditandai oleh kurangnya perbedaan antar individu dan antar kelompok, serta makin eratnya persatuan aksi, sikap, dan proses mental yang berhubungan dengan kepentingan bersama (Harsojo, 1984). Guy T. Petherbridge (1989) menyatakan bah-wa prinsip rumah tinggal masyarakat Arab antara lain adanya pembagian ruang publik dan ruang privat, adanya pintu samping, dan kebe-radaan courtyard. Edward T. Hall (1966) menjelaskan bahwa pembagian ruang dilakukan karena budaya yang berkembang di masyarakat Arab tentang persepsi publik dan privat, bukan karena agama. Ruang publik biasanya diperun-tukkan bagi ruang laki-laki (birun) untuk menerima tamu dan bekerja. Sedangkan ruang privat diperuntukkan bagi wanita (anderun/ha-rem) seperti ruang tidur, ruang keluarga, ruang makan, dan dapur. Pemisahan ruang tersebut didukung dengan 
pemberian akses masuk un-tuk wanita menuju ke ruang privat berupa pintu samping. Di belakang rumah terdapat halaman/ courtyard (Berg, 1989) sebagai respon iklim Arab yang panas kering di siang hari. L.W.C. van den Berg (1989) mengatakan bahwa pera-bot orang kaya maupun miskin di Yaman sangat sederhana; orang duduk di lantai yang ditutup permadani atau tikar dengan bantal. Klen besar patrilineal (keturunan keluarga) amat jelas eksistensinya pada orang Arab di mana pun dia berada dan gambaran ini meru-pakan karakteristik yang dominan dari orang Arab di tanah asal mereka, Hadhramaut. Ma-syarakat Hadhramaut hidup dalam kelompok-kelompok yang dinamakan qabilah yaitu kelompok patrilineal (Shahab, 2005). Kebang-gaan dan kepedulian sebagai anggota satu klen tampak pada kepedulian mereka untuk menge-tahui dan menyimpan silsilah keluarga. Meru-pakan hal yang biasa di rumah orang Arab memiliki silsilah keturunan yang dijadikan hiasan dinding di rumahnya (Shahab, 2005).

Salah satu perwujudan ajaran Islam pada rumah tinggal adalah mengaplikasikan hijab. Hijab/tabir adalah penutup atau sesuatu yang memisahkan/membatasi baik berupa tembok, bilik, korden, kain dan lain-lain (Mulhandy dkk, 1992). Islam mengharamkan patung sebagai dekorasi di dalam rumah orang Islam. Konsep rumah dalam peradaban Islam antara lain memiliki tabhane yaitu ruang utama sebagai tempat menerima tamu dan courtyard yaitu taman di dalam rumah (Susanti, 2014).

Arsitektur Tropis adalah suatu konsep bangunan yang mengadaptasi kondisi iklim tropis. Indonesia memiliki iklim yang tergolong iklim topis panas lembap. Faktor iklim yang mempengaruhi kenyamanan pada bangunan antara lain radiasi matahari, curah hujan, temperatur, ke-lembapan, dan gerakan udara. Penggunaan tritisan, atap miring, dan warna cat terang merupakan respon dari terik matahari dan curah hujan yang tinggi. Sinar matahari dapat dimanfaatkan sebagai pencahayaan alami dengan respon bangunan berupa penggunaan bukaan (jendela, pintu, bouvenlight) berjumlah banyak dan melalui orientasi serta bentuk denah bangunan. Pengha-waan alami pada bangunan didukung dengan penggunaan dan peletakan bukaan (jendela, pintu, lubang angin) untuk memungkinkan terjadinya ventilasi silang. (Rahim, 2012)

Arsitektur kolonial adalah arsitektur cangkokan dari negeri induknya Eropa ke daerah jajahan-nya, dan arsitektur kolonial Belanda adalah arsitektur Belanda yang dikembangkan di Indo-nesia (Soekiman,2011). Arsitektur kolonial Belanda adalah gaya desain yang dipopularkan oleh Belanda, memiliki ciri antara lain tampak simetris, material dari batu bata atau kayu tanpa pelapis, entrance mempunyai dua daun pintu, pintu masuk terletak di samping bangu-nan, denah simetris, jendela besar berbingkai kayu, dan terdapat dormer/bukaan pada atap (Wardani, 2009). Elemen arsitektur lainnya yang sering digunakan pada arsitektur kolonial adalah gavel (gable), dinding tebal, ornament dekoratif (ragam hias), dan jendela tinggi. Gaya bangunan kolonial empire style diterapkan pada bangunan rumah tinggal yang disebut landhuis. Landhuis berasal dari kata landhuizen yaitu gaya hidup yang berasal dari akulturasi budaya Belanda dengan pribumi yang cukup mampu meniru tata cara hidup Belanda, dalam hal ini adalah style rumah tinggalnya (Soekiman, 2000). Ciri-ciri gaya ini adalah denah simetri, beratap perisai, berkesan terbuka, terdapat pilar di serambi depan dan belakang, di dalam rumah terdapat serambi tengah atau lorong menuju ke ruang tidur. Serambi belakang sering digunakan sebagai ruang makan yang terhubung ke daerah servis yang terpisah dari massa utama. Organisasi ruang rumah landhuis dapat dilihat pada gambar 1. Sekitar tahun 1920, arsitek kolonial Belanda melakukan penyesuaian dengan iklim tropis Indonesia. Aliran gaya seni Eropa seperti art and craft, art nouveau, dan art deco yang menjadi tren pada periode tertentu berpengaruh pada gaya arsitektur kolonial yang dibangun di Indonesia.

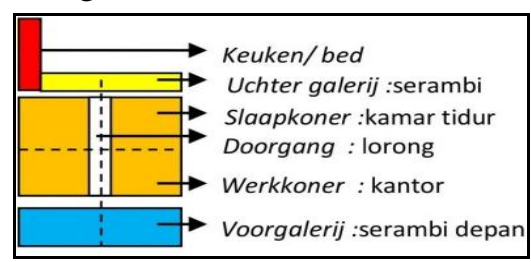

Gambar 1. Organisasi rumah kolonial Sumber : Frick, 1997. 


\section{METODE}

Penelitian mengenani fenomena peleburan budaya yang terjadi pada arsitektur rumah tua etnis Arab tergolong penelitian kualitatif. Menurut Moleong (2007), penelitian kualitatif adalah penelitian yang bermaksud untuk memahami fenomena tentang apa yang dialami oleh subjek penelitian secara holistik, dan dengan cara deskripsi dalam bentuk kata-kata dan bahasa, pada suatu konteks khusus yang alami-ah dan dengan memanfaatkan berbagai metode alamiah. Studi dilakukan dengan melihat ele-men-elemen pada bangunan, yang disebut se-bagai penelitian eksploratif (penjajagan). Menurut Irawan (2007), penelitian eksploratif adalah penelitian yang digunakan untuk me-ngumpulkan data-data awal tentang sesuatu. Identifikasi elemen arsitekur dilakukan dengan metode deksriptif. Masih menurut Irawan (2007), metode deskriptif digunakan untuk mengkaji sesuatu seperti apa adanya atau pola hubungan antara dua atau lebih variabel. Sumber studi berupa data primer yang didapat dari observasi lapangan untuk melakukan pe-ngamatan fisik rumah dan melalui wawancara, serta data sekunder yang didapat dari studi kepustakaan. Pengumpulan data bangunan menggunakan metode purposive sampling, ka-rena data rumah yang diambil sebagai sampel hanya rumah tua etnis Arab yang sesuai dengan kriteria bangunan cagar budaya dan berada di kawasan Kampung Arab Pasar Kliwon.

Eksplorasi dilakukan pada tiga rumah (gambar 2) sebagai sampel untuk dieksplorasi pada studi identifikasi hasil akulturasi budaya melalui elemen rumah tua etnis Arab di Kampung Arab Pasar Kliwon. Bangunan yang dipilih merupa-kan rumah yang berusia lebih dari 50 tahun dengan pemilik beretnis Arab yang berada di kawasan Kampung Arab Pasar Kliwon.

\section{A. Rumah I}

Rumah milik Bapak Umar Arfan (beretnis Arab) berada di Jalan Kapten Mulyadi, Kampung Gurawan. Bangunan ini awalnya hanya berfungsi sebagai hunian, namun kini rumah bagian depan dikembangkan untuk aktivitas ekonomi menjadi toko gorden dan busana mus-lim. Perubahan fungsi mengakibatkan adanya perubahan penggunaan ruang, elemen interior, dan tampilan eksterior bangunan pada bagian depan. Diketahui dari pemilik rumah bahwa rumah ini berusia lebih dari enam puluh tahun.

\section{B. Rumah II}

Rumah ke-2 adalah milik Bapak Shahab Mulahela (beretnis Arab) yang berada di Jalan Ibu Pertiwi, Kampung Gurawan. Bangunan ini dulu berfungsi sebagai hunian. Kini rumah tersebut digunakan sebagai tempat menginap bagi para tamu Bapak Shahab. Rumah ini dibangun pada tahun 1950 dan diwariskan kepada putranya oleh sang ayah, Abdul Kadir Mulahela. Beliau adalah kerabat dan wakil imam dari Habib Alwi Al-Habsyi di Masjid Riyadh. Beliau lebih dari 20 tahun menjadi imam dan wakil imam di Masjid Riyadh. Saat beliau masih hidup, rumah ini sering digunakan untuk kegiatan agama, seperti majlis taklim dan san-tunan, serta sebagai tempat singgah dan ber-kumpul teman dan kerabat. Kegiatan keagama-an di rumah ini masih sering dilakukan hingga sekarang. Perubahan pada bangunan terjadi pada plafon dan lantai massa utama. Massa zona servis (ruang belakang) telah dibangun ulang dengan pintu jendela yang masih asli, serta tampilan yang mirip dengan aslinya.

\section{Rumah III}

Rumah ke-3 juga berada di Jalan Ibu Pertiwi, Kampung Gurawan. Pemiliknya adalah Bapak

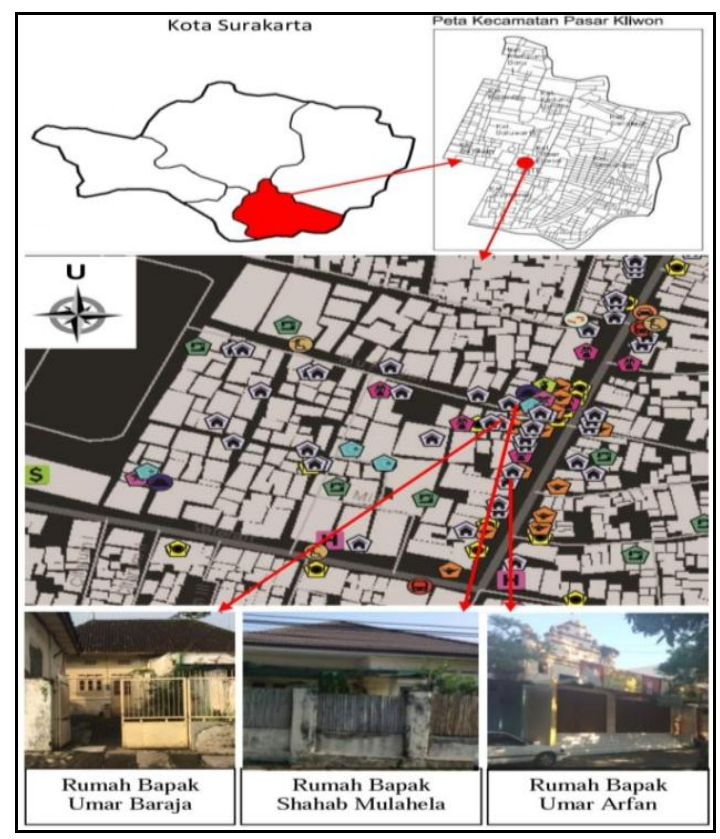

Gambar 2. Sampel rumah tua etnis Arab di Kampung Arab Pasar Kliwon. 
Umar Baraja yang beretnis Arab. Bangunan ini berfungsi sebagai rumah tinggal yang dihuni oleh lima orang dan seorang asisten rumah tangga. Massa terpisah di depan dulu berfungsi sebagai wadah aktivitas ekonomi, namun kini tidak difungsikan lagi. Rumah ini berusia lebih dari 60 tahun dan diwariskan oleh ayah kepada anaknya. Bangunan ini tidak mengalami peru-bahan signifikan pada bagian fisik, sehingga keaslian bangunan masih dapat dinikmati.

\section{HASIL DAN PEMBAHASAN}

Elemen bangunan yang dibahas adalah yang masih asli dan atau direkonstruksi seperti asli.

\subsection{Pola Ruang}

\section{A. Organisasi ruang}

Ketiga rumah memiliki organisasi ruang yang hampir sama, yaitu rumah terbagi menjadi massa utama dan massa zona servis (kecuali rumah III dengan tambahan massa toko) (lampiran 1). Massa utama terdiri dari ruang untuk aktivitas ekonomi dan atau menerima tamu pada bagian depan, dilanjutkan dengan kamarka-mar yang dihubungkan lorong atau serambi te-ngah, dan serambi belakang untuk ruang ma-kan. Zona servis seperti dapur, kamar mandi, ruang cuci, dan kamar tidur pembantu berada di belakang dan terpisah dari massa utama. Peruangan ini menyerupai organisasi ruang rumah kolonial seperti ilustrasi pada gambar 2.

B. Bentuk denah

Denah ketiga rumah memiliki bentuk tipis dan memanjang (lampiran 1). Bentuk ini memungkinkan tiap ruang untuk mendapat pencahayaan dan penghawaan alami, memanfaatkan iklim tropis Indonesia. Bentuk bangunan yang terli-hat langsing dan kurus (streamline) juga meru-pakan karakter gaya art deco yang diadaptasi pada bangunan kolonial Belanda di Indonesia.

C. Pembatas zona

Terdapat aturan tidak tertulis mengenai pemba-gian zona pada rumah etnis Arab. Ruang bagi-an depan seperti ruang ekonomi dan ruang ta-mu merupakan zona publik yang diperuntukan bagi pria. Ruang bagian belakang seperti ruang keluarga, kamar tidur, dapur, dan ruang makan merupakan zona privat yang diperuntukkan bagi wanita. Hal ini sama dengan kondisi ru-mah di Arab yaitu di antara zona tersebut biasa diberi pembatas yang tegas seperti pintu atau tirai. Pada ketiga kasus rumah digunakan pem-batas berupa pintu (lampiran 2). Pintu ini ber-fungsi sebagai hijab untuk menutupi kegiatan di dalam rumah, sesuai prinsip arsitektur Islam.

\section{Pintu samping}

Side entrance sebagai pintu masuk kedua beru-pa pintu samping terlihat pada ketiga rumah ini. Rumah I dan rumah II memiliki pintu samping yang sejajar dengan bagian depan massa uta-ma, tersambung ke zona servis melalui lorong. Sedangkan pintu samping pada rumah III me-nempel pada massa zona servis yang dapat diakses dari halaman samping. Pintu samping berfungsi sebagai akses masuk untuk wanita menuju ke ruang privat. Keberadaan pintu sam-ping adalah respon dari adanya pembagian zo-na publik dan privat yang merupakan karakter dari arsitektur di Arab. Posisi pintu samping dapat dilihat pada lampiran 1, sedangkan tampilannya dapat dilihat pada lampiran 3 .

\section{E. Courtyard}

Kesamaan lain ditemukan pada ketiga rumah yaitu keberadaan taman di dalam rumah/courtyard pada bagian belakang rumah (lampiran 1 dan 4). Keberadaan courtyard di belakang rumah sesuai dengan karakter rumah di Yaman dan konsep rumah dalam peradaban Islam.

F. Pintu butulan

Pintu butulan adalah pintu tembusan dari samping atau belakang rumah. Pintu semacam ini ditemukan di ketiga rumah untuk menghubung-kan rumahnya dengan rumah tetangganya. Pin-tu butulan pada rumah I berada di koridor ru-ang belakang; pintu butulan pada rumah II berada di courtyard ruang belakang (kini hanya bekasnya); sedangkan pada rumah III berada di halaman samping (lampiran 1 dan 5). Penggu-naan pintu ini diperkirakan karena terbawanya karakter orang Yaman yang suka hidup dalam kelompok patrilineal. Saat berhijrah ke Indone-sia, masyarakat Hadhramaut yang berhubungan keluarga maupun tidak, semuanya merasa saling bersaudara karena adanya kesamaan asal tanah air. Sehingga dibuatlah pintu butulan antarrumah etnis Arab yang bertetangga. 


\section{G. Ruang kegiatan ekonomi}

Mata pencaharian sebagai pedagang merupakan bagian dari kebudayaan etnis Arab. Hal ini didukung pula anjuran dalam Agama Islam untuk berdagang. Kegiatan perdagangan pada masyarakat etnis Arab menyebabkan hunian mereka juga merangkap sebagai tempat terjadi-nya transkasi jual beli, sehingga terdapat ruang untuk kegiatan ekonomi. Beberapa tahun lalu dilakukan renovasi pada ruang-ruang depan di rumah I untuk adaptasi ruang sebagai wadah kegiatan ekonomi. Ruang-ruang tersebut di-fungsikan sebagai toko untuk tempat berda-gang pakaian muslim dan tirai/gorden. Wadah kegiatan ekonomi juga ditemukan pada rumah III. Terdapat massa terpisah di bagian depan tapak yang dulunya berfungsi sebagai toko.

$\mathrm{H}$. Ruang menerima tamu

Rumah I dan II memiliki ruang keluarga yang cukup luas. Selain sebagai tempat bersantai bagi penghuni, ruang ini biasa digunakan untuk menerima tamu keluarga dekat dan atau tempat penghuni wanita menerima tamu wanita (lam-piran 1 dan 6). Ruang dengan fungsi seperti itu kini tidak ada pada rumah III karena perubahan fungsi ruang tersebut menjadi kamar tidur. Ruang ini sesuai dengan konsep rumah dalam peradaban Islam yang memiliki tabhane yaitu ruang utama sebagai tempat menerima tamu.

\subsection{Elemen Interior Ruang}

\section{A. Posisi pintu dan jendela}

Pintu dan jendela pada ketiga rumah diposisikan sedemikian rupa agar memungkinkan terja-dinya ventilasi silang pada tiap bagian bangu-nan untuk memanfaatkan pencahayaan dan penghawaan alami. Ketiga rumah memiliki jumlah jendela yang cukup banyak. Hampir tiap ruang terpasang jendela (lampiran 1). Pintu dan jendela pada ketiga rumah merupakan adaptasi dari iklim tropis di Indonesia.

B. Lubang angin

Hampir setiap ruang pada ketiga rumah mengaplikasikan lubang angin, sebagai ventilasi udara untuk memungkinkan sirkulasi keluar masuknya udara. Lubang angin pada ketiga rumah memiliki tampilan yang bervariasi (lampiran 7). Penggunaan lubang angin merupakan respon terhadap iklim tropis.

\section{Bovenlicht}

Bovenlicht merupakan bukaan yang posisinya lebih tinggi dibanding pintu dan atau jendela. Rumah I dan III menggunakan bovenlicht yang dipasang menyatu di atas beberapa pintu berupa lubang dengan terali vertikal dan horizontal. Ruang tanpa jendela di rumah I menggunakan bovenlicht berlubang yang terpisah dari pintu (lampiran 8). Bovenlicht berlubang tersebut memungkinkan pencahayaan dan penghawaan alami masuk ke dalam ruang, sebagai respon untuk memanfaatkan iklim tropis. Kedua rumah tersebut juga menggunakan bovenlicht bentuk lengkung dengan penutup kaca (lampiran 9). Elemen tersebut mirip dengan bovenlicht di Eropa yang berfungsi memasukkan cahaya matahari dan menjaga ruang dari suhu dingin.

D. Kaca patri

Kaca patri digunakan sebagai material bovenlicht pada rumah I dan III . Kaca ini juga digunakan sebagai ornamen pada pintu di rumah I dan II (lampiran 9). Penggunaan kaca patri pada ketiga rumah dikarenakan mengikuti tren arsitektur pada masa kolonial yang diperkenalkan Belanda saat masuk ke Indonesia.

E. Tegel

Lantai di rumah I dan III menggunakan materi-al tegel berukuran 20x20 cm. Berdasar hasil wawancara, rumah II dulu juga menggunakan material lantai yang sama, namun sudah dire-novasi dan diganti menggunakan keramik. Penggunaan tegel pada rumah II masih dapat dilihat pada reruntuhan bekas dapur dan kamar anak. Tegel adalah jenis lantai yang terbuat dari bahan dasar berupa campuran pasir dan semen. Tegel yang digunakan pada rumah I adalah tegel dengan motif flora bervariasi dan tegel polos yang ditata dengan pola tertentu. Sedangkan pada rumah III digunakan tegel polos berwarna abuabu dan kuning yang ditata membentuk pola tertentu (lampiran 10). Peng-gunaan tegel diperkenalkan oleh Belanda dan menjadi karakter dari bangunan kolonial. Permukaan tegel memberi efek dingin dan tidak memantulkan panas karena tidak licin, sehingga dapat menjaga suhu di dalam rumah dan sesuai dengan iklim tropis di Indonesia. 


\section{F. Dinding tebal}

Massa utama pada ketiga rumah memiliki dinding dengan tebal $30 \mathrm{~cm}$. Dinding tebal seperti ini merupakan salah satu karaker dari arsitektur bangunan kolonial.

G. Plafon

Massa utama pada rumah I dan III menggunakan triplek sebagai material plafon. Plafon pada rumah II direnovasi dan diganti menggunakan plafon gypsum. Ruang makan rumah I dan massa utama rumah III menggunakan plafon triplek dengan balok kayu vertikal dan horizontal yang diekspos (lampiran 11). Plafon seperti ini termasuk karakter dari gaya art deco dan art nouveau yang merupakan tren gaya bangunan kolonial Belanda di Indonesia.

H. Perabot

Ruang keluarga pada rumah I menggunakan perabot berupa amben dan bantal, sedangkan pada rumah II menggukan karpet (lampiran 6). Perabot seperti ini sama dengan perabot yang digunakan pada rumah di Yaman.

I. Foto keluarga

Pada ruang tamu rumah I dan III ditemui foto orang tua pemilik rumah yang berasal dari $\mathrm{Ha}-$ dhramaut (lampiran 12). Penggunaan silislah keluarga sebagai hiasan dinding di rumah mirip dengan kondisi di Yaman. Kasus berbeda dite-mui pada rumah II yaitu hiasan dinding berupa foto habib (lampiran 12). Dituliskan oleh Sha-hab (2005) bahwa foto ulama sering digunakan sebagai hiasan dinding di rumah maupun di tempat kerja oleh masyarakat Arab di Indone-sia. Hal ini dikarenakan habib dianggap seba-gai panutan, terutama oleh golongan sayid.

\section{J. Dekorasi islami}

Kaligrafi berupa tulisan potongan ayat $\mathrm{Al}-$ Qur'an atau simbol Allah dan Muhammad, serta foto Masjid al-Haram digunakan sebagai dekorasi pada beberapa ruang di ketiga rumah. Dekorasi tersebut digantung di dinding (lampiran 13). Penggunaan dekorasi islami sesuai dengan konsep rumah dalam peradaban Islam yang tidak memakai patung sebagai dekorasi.

\subsection{Elemen Eksterior Bangunan}

\section{A. Tampilan Pintu}

Ketiga rumah menggunakan tipe pintu kayu dengan dua daun pintu. Pintu tersebut berpanel dengan pola geometris dan bermotif garis lurus (lampiran 14). Pola geometris dan streamline sesuai dengan karakter art deco yang menjadi salah satu tren bangunan kolonial di Indonesia.

B. Tampilan Jendela

Salah satu tipe jendela pada rumah I menggunakan krepyak (jalusi) yang memungkinkan udara dan cahaya masuk ke dalam ruang walau jendela dalam keadaan tertutup, serta menurun-kan perambatan panas ke dalam ruang (lampi-ran 15). Jendela krepyak sering ditemui pada rumah tua etnis Arab di Kampung Arab Pasar Kliwon. Jendela ini diperkirakan diperkenalkan oleh Belanda karena jendela tersebut sering ditemui pada bangunan tua di Eropa dan ba-ngunan kolonial Belanda di Indonesia. Jendela krepyak sesuai dengan iklim tropis Indonesia.

Rumah I dan III memiliki tipe jendela berlapis tiga (lapis I jendela kaca; lapis II jendela kayu tertutup sebagian; lapis III jendela kayu tertutup penuh) yang memberi fleksibilitas penggunaan jendela, menyesuaikan kondisi cuaca dan penggunaan ruang (lampiran 15). Sedangkan jendela pada rumah II terdiri dari 2 lapis (lapis I jendela kaca; lapis II jendela kayu). Jendela berlapis diperkirakan diperkenalkan oleh Belanda karena sering ditemui pada bangunan di Eropa, yang berfungsi menyesuaikan cuaca pada empat musim.

Jendela ketiga rumah memiliki kesamaan yaitu tiap bingkai jendela terdiri dari dua panel, atas dan bawah, yang dapat dibuka-tutup secara ter-pisah (lampiran 15). Jendela tersebut banyak di-temui pada rumah tua di Surakarta. Diperkira-kan penggunaan jendela tipe ini di ketiga rumah dikarenakan tren pada periode tersebut. Jendela ini sesuai dengan iklim tropis. Bila sinar mata-hari terik, panel atas ditutup untuk menghalangi panas, dan angin masuk dari panel bawah.

C. Terali

Jendela pada ketiga rumah dilengkapi dengan terali besi. Terali digunakan sebagai pengaman dan hiasan. Penggunaan material logam berupa besi sebagai terali diperkenalkan oleh Belanda. Terali ketiga rumah berpola sama berupa susu-nan besi vertikal dengan besi horizontal yang membagi bagian tengahnya (lampiran 15). Pola geometris dan streamline terali tersebut sesuai dengan karakter art deco, 
yang menjadi salah satu tren bangunan kolonial di Indonesia.

D. Dekorasi dinding

Ketiga rumah memiliki dekorasi dinding dari beton pada eksterior bangunan. Dekorasi yang digunakan berupa streamline dan bentuk geometris (lampiran 16). Pola seperti itu sesuai dengan karakter art deco yang menjadi salah satu tren dari bangunan kolonial di Indonesia.

\section{E. Gavel / Gable}

Gable adalah bentuk segitiga atau bentuk lainnya mengikuti konstruksi atap yang berada pada ujung bangunan (Sumalyo, 1993). Terlihat ga-vel yang mengikuti bentuk atap pelana pada bagian belakang atap massa utama rumah I dan bagian depan atap massa toko rumah III (lam-piran 17). Keduanya dihiasi pola geometris yang sama berupa garis yang membentuk segi-tiga dengan lingkaran di dalamnya. Sedangkan pada bagian depan atap massa utama rumah I menggunakan stepped gable, yaitu gable yang berundak. Gable tersebut tidak mengikuti ben-tuk atap dan hanya digunakan sebagai dekorasi. Penggunaan gable/gavel merupakan salah satu karakter dari bangunan kolonial Belanda.

\section{F. Warna}

Ketiga rumah menggunakan warna pastel terang. Rumah I berwarna biru muda; rumah II berwarna putih; rumah 3 berwarna krem (lampiran 16). Penggunaan warna pastel sesuai dengan karakter art nouveau dari Eropa yang menjadi salah satu tren bangunan kolonial di Indonesia. Di sisi lain, penggunaan warna terang juga sesuai dengan karakter arsitektur tropis. Warna terang memiliki penyerapan radiasi matahari yang kecil, jadi rumah tidak panas. Warna cat pada bagian toko rumah 1 diganti warna kuning-krem agar lebih menarik.

\section{G. Bentuk Atap}

Atap yang digunakan pada ketiga rumah adalah atap miring yang sesuai untuk daerah berikilim tropis dengan curah hujan yang cukup tinggi. Atap miring berfungsi untuk mengalirkan air hujan. Kemiringan atap tidak terlalu curam se-perti di Eropa yang berfungsi agar salju turun dengan cepat. Kemiringan atap digunakan un-tuk menyimpan panas antara atap dan plafon, sehingga panas tidak langsung masuk ke ruang di bawahnya. Rumah I beratap pelana pada massa utama dan beratap sandar pada zona ser-vis; rumah II beratap limasan pada massa uta-ma dan beratap sandar pada zona servis; rumah III beratap pelana pada massa toko dan beratap limasan pada massa utama (lampiran 17).

H. Teritis

Teritis atau tritisan (overstek, awning) merupa-kan bagian dari bangunan atap tambahan yang berdiri sendiri atau berupa perpanjangan dari atap utama (Sukawi, 2008). Ketiga rumah me-makai teritis sebagai perpanjangan atap dengan panjang $\pm 80 \mathrm{~cm}$ (lampiran 17). Penggunaan te-ritis sesuai dengan iklim tropis Indonesia. Teri-tis dapat melindungsi dari tempias air hujan serta mengalirkan air hujan. Selain itu, teritis juga dapat menjadi pembayang sinar matahari.

I. Genteng Tanah Liat

Ketiga rumah menggunakan genteng tanah liat sebagai material penutup atap (lampiran 17). Penggunaan genteng tanah liat di Indonesia digalakan oleh pemerintah Belanda pada masa penjajahan, dengan alasan kesehatan. Genteng tanah liat sesuai dengan iklim tropis Indonesia karena dapat menyesuaikan kondisi cuaca, yaitu membuat ruang sejuk saat cuaca panas dan memberi kehangatan saat cuaca dingin.

\section{J. Selasar}

Ruang-ruang pada zona servis di ketiga rumah diakses melalui selasar (lampiran 18). Selain sebagai sirkulasi, selasar juga berfungsi menghalau sinar matahari yang masuk sehingga temperatur ruangan lebih rendah. Penggunaan selasar sesuai dengan iklim tropis Indonesia.

\section{K. Tampilan Ruang Belakang}

Ruang belakang ketiga rumah terpisah dari massa utama. Pada rumah I dan II, tampilan ru-ang belakang terdiri dari selasar dan atap san-dar yang ditopang kolom-kolom kayu (lampi-ran 18). Tampilan yang demikian menyerupai tampilan arsitektur lokal di Jawa. Tampilan ruang belakang pada rumah III berbeda dikare-nakan terdiri dari dua lantai.

\section{Pagar}

Pagar pada rumah II berupa kombinasi beton dan bambu yang tertutup dengan tinggi $\pm 2 \mathrm{~m}$. Sedangkan pagar pada rumah III berupa kombinasi beton dan terali besi yang tidak masif dengan tinggi $\pm 2 \mathrm{~m}$. Pagar tinggi tertutup ini dikarenakan adanya konflik antara etnis Arab dengan masyarakat pribumi pada masa lalu. 
Politik adu domba Belanda terhadap antar etnis di Indonesia memberikan akibat meskipun te-lah merdeka dari Belanda. Beberapa kali kon-flik terjadi pada tahun 1970-an, antara komuni-tas etnis Arab dengan pribumi di Surakarta, akibat perasaan saling curiga (Hastuti, 2008). Diperkeruh lagi oleh peristiwa kerusuhan Mei 1998 di Solo dengan kaum etnis minoritas menjadi korbannya. Rumah I kini tidak mem-punyai pagar karena adanya renovasi rumah menjadi toko. Dulu rumah ini memakai pagar beton rendah. Pagar rendah tersebut sama kon-disinya dengan masyarakat Jawa pada umum-nya yang memfungsikan pagar hanya sebagai pembatas rumah. Pagar seperti ini terlihat pada beberapa rumah tua etnis Arabdi Pasar Kliwon.

\section{KESIMPULAN}

Rumah tinggal sebagai wadah terjadinya kegia-tan sehari-hari seseorang, selalu diwarnai oleh karakteristik kebudayaan penghuninya. Pele-buran budaya (akulturasi) Arab, Islam, Indone-sia, dan Belanda ditemukan pada elemen arsi-tektur rumah tua etnis Arab di Kampung Arab Pasar Kliwon. Hal tersebut dapat terlihat dari adanya eklektisme (percampuran) elemen arsi-tektur rumah tinggal Arab (khususnya Yaman), arsitektur rumah islami, arsitektur tropis Indonesia, dan arsitektur kolonial Belanda pada pola ruang, elemen interior, dan eksterior rumah. Budaya dalam berkehidupan sehari-hari $\mathrm{Ha}$ dhrami dibawa saat bermigrasi ke Indonesia dan diterapkan pada perancangan dan penataan rumah tinggal. Karakter arsitektur rumah ting-gal di Arab, khususnya Yaman, terlihat melalui keberadaan pintu samping, courtyard, perabot berupa karpet atau amben, dan foto keluarga pada rumah tua etnis Arab di Kampung Arab Pasar Kliwon. Adapun elemen arsitektur yang muncul akibat karakter budaya etnis Arab di Indonesia yaitu adanya pintu butulan, ruang kegiatan ekonomi, dan foto ulama/habib.

Kepercayaan atau agama merupakan unsur kebudayaan yang menjadi dasar dan paling susah untuk berubah. Konsep agama diterapkan oleh imigran Hadhrami yang beragama Islam pada perancangan dan penataan rumah tinggal. Karakter arsitektur berkonsep Islam terlihat dengan keberadaan pembatas fisik antara zona publik dan privat, courtyard, ruang menerima tamu (tabhane), dan dekorasi islami pada rumah tua etnis Arab di Kampung Arab Pasar Kliwon. Budaya Islam juga terlihat dengan adanya ru-ang kegiatan ekonomi untuk berdagang.

Adaptasi perlu dilakukan saat makhluk hidup menempati habitat baru. Begitu pula imigran Hadhrami yang menetap dan bertempat tinggal di Indonesia. Adaptasi terhadap iklim tropis lembab di Indonesia dilakukan pada peranca-ngan rumah tua etnis Arab di Kampung Arab Pasar Kliwon yang menggunakan jendela dan pintu untuk ventilasi silang, lubang angin, bovenlicht berlubang, berdenah tipis, genteng tanah liat, berwarna terang, atap miring, teritis, dan selasar. Kondisi dan budaya lokal juga berpengaruh pada tampilan ruang belakang, jende-la 2 panel (atas-bawah), dan ketinggian pagar.

Keberadaan penjajah Belanda memberikan pengaruh pada pola hidup masyarakat di Indonesia seperti dalam hal bermukim. Aliran seni Eropa menjadi tren gaya bangunan yang diperkenalkan oleh arsitek-arsitek Belanda dan dike-nal sebagai arsitektur kolonial. Bangsawan dan saudagar kaya seringkali meniru gaya tersebut untuk rumah tinggalnya yang disebut rumah landhuis. Begitu pula orang keturunan Arab yang pada masa itu sudah banyak yang bersta-tus ekonomi tinggi. Karakter arsitektur kolonial Belanda pada rumah tua etnis Arab di Kam-pung Arab Pasar Kliwon terlihat pada organi-sasi ruang, kaca patri, dinding tebal, plafon, tampilan pintu, terali besi, dekorasi dinding eksterior, dan gavellgable. Adapun elemen arsitektur kolonial Belanda pada rumah tua etnis Arab yang sesuai dengan kondisi iklim tropis yaitu jendela krepyak, jendela berlapis, tegel, berdenah tipis, bovenlict kaca, berwarna pastel terang, dan genteng tanah liat.

\section{DAFTAR PUSTAKA}

Ashworth, G.J, B.J. Graham, J.E. Tunbridge. (2007). Pluralising Pasts: Heritage, Identity and Place in Multicultural Societies. London : Pluto. 
Bazher, Najmi Muhamad, Kusumaningdyah Nurul Handayani, Tri Yuni Iswati. (2017). Penerapan Sense of Place sebagai Upaya Konservasi Kawasan : Studi Kasus pada Kampung Arab Pasar Kliwon. Arsitektura, Vol.15, No. 2. http://dx.doi.org/10.20961/arst.v15i2. 15204

Christian, F. (1992). Wujud Arsitektur sebagai Ungkapan Sosial Budaya Manusia. Yogyakarta : Universitas Atmajaya.

Frick, Heinz. (1997). Pola Struktural dan Teknik Bangunan di Indonesia. Yogyakarta : Yayasan Kanisius.

Harsojo. (1984). Pengantar Antropologi. Bandung : Binacipta.

Hastuti, Fajar Endang. (2008). "Potensi dan Pengembangan Kampung Etnik Arabsebagai Aset Wisata di Surakarta”, Laporan Tugas Akhir. Program Studi Usaha Perjalanan Wisata FSSR UNS.

Ibn Haj, Mulhany dkk. (1992). Enam Puluh Satu Tanya Jawab tentang Jilbab. Bandung : Espe Press

Irawan, Prasetya. (2007). Penelitian Kualitatif dan Kuantitatif untuk Ilmu-ilmu Sosial. Depok:Dep. Ilmu Administrasi FISIP UI.

Kesheh, Natalie. (2007). Hadhrami Awakening Kebangkitan Hadhrami Indonesia. Jakarta : Akbar.

Moleong, Lexy. (2007). Metode Penelitian Kualitatif. Bandung:PT Remaja Rosda Karya

Kluckhohn, Clyde. (1953). Universal Categories of Culture. Chicago : University Press.

Koentjaraningrat, (1985). Pengantar Ilmu Antropologi. Jakarta : Aksara Baru.

Petherbridge, Guy T. (1989). Vernacular Architecture: The House and Society.

Prasetyo, Himawan. (2001). "Wajah Kauman Surakarta 1910-1930”, Skripsi. Jurusan Ilmu Sejarah FIB UGM.

Rahim, R. (2012). Fisika Bangunan untuk Area Tropis. Bogor : IPB Press.

Rapoport, Amos. (1981). Identity and environment: A Cross-Cultural Perspective. In Housing and Identity: CrossCultural Perspecrives. Diedit oleh J. S, Duncan, London: Croom Helm.
Shahab, Yasmine Zaki. (2005). Sistem Kekerabatan sebagai Katalisator Peran Ulama. Keturunan Arab di Jakarta dalam Antropologi Indonesia, Vol. 29, No. 2.

Soekiman, Djoko. (2011). Kebudayaan Indis: Dari Zaman Kompeni sampai Revolusi Jakarta : Komunitas Bambu.

Soekiman, Djoko. (2000). Kebudayaan Indis. Yogyakarta : Bentang.

Sumalyo, Yulianto. (1993). Arsitektur Kolonial Belanda di Indonesia. Yogyakarta : Gadjah Mada University Press.

Susanti, Anna. (2014). Membangun Rumah dengan Perspektif Islam. Bandung : Oase Buku

T. Hall, Edward. (1966). The Hidden Dimension. USA : Doubleday \& Company.

Usman, S. (2009). Perjalanan Sejarah Ekonomi Indonesia.

Van den Berg, L.W.C. terjemahan Rahayu Hidayat. (1989). Hadhramaut dan Koloni Arab di Nusantara. Jakarta : INIS.

Wardani, Laksmi Kusuma. (2009). Gaya Desain Kolonial Belanda Pada Interior Gereja Katolik Hati Kudus Yesus Surabaya. Universitas Kristen Petra. Surabaya. 


\section{LAMPIRAN}

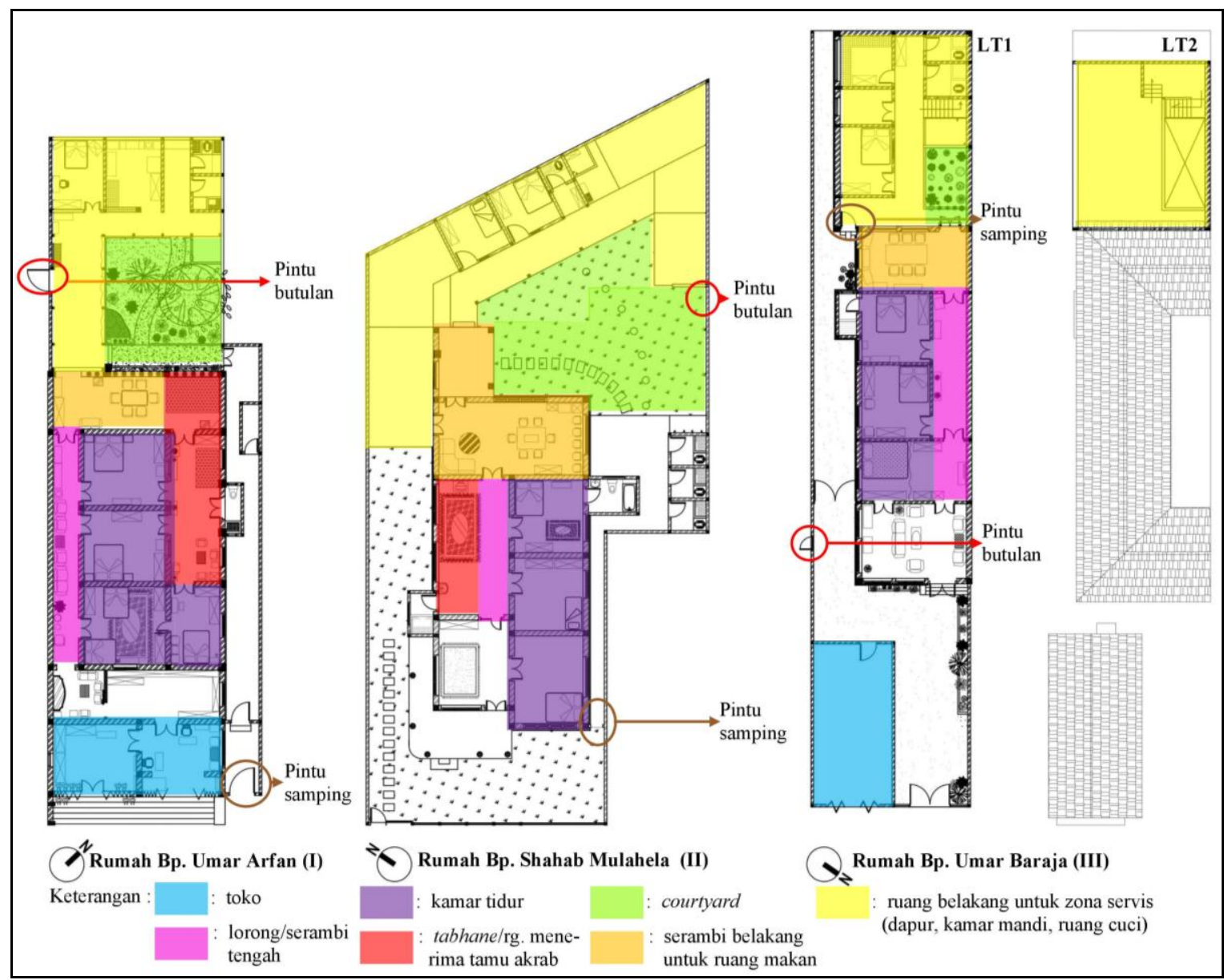

Lampiran 1. Pola ruang rumah tua etnis Arab di Kampung Arab Pasar Kliwon yang menjadi kasus studi,

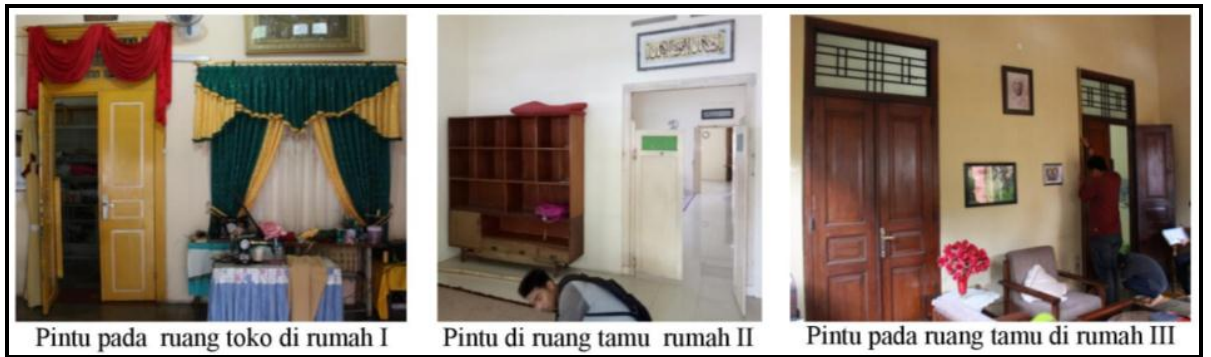

Lampiran 2. Pintu pembatas antara zona publik dan privat pada rumah tua etnis Arab di Kampung Arab Pasar Kliwon, sebagai hijab untuk menutupi kegiatan privat sesuai prinsip arsitektur Islam,

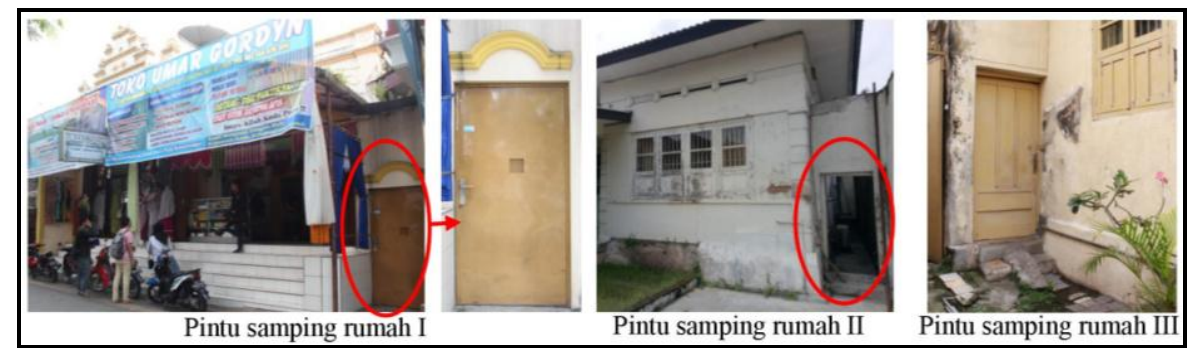

Lampiran 3. Pintu samping sebagai akses masuk untuk wanita menuju ke ruang privat, mendukung pembagian zona publik-privat sesuai karakter arsitektur di Arab, 

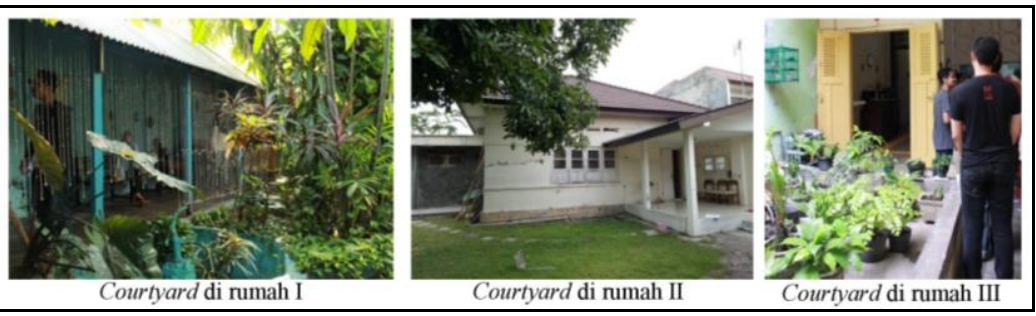

Lampiran 4. Courtyard di belakang rumah sesuai karakter rumah di Arab dan rumah dalam peradaban Islam,
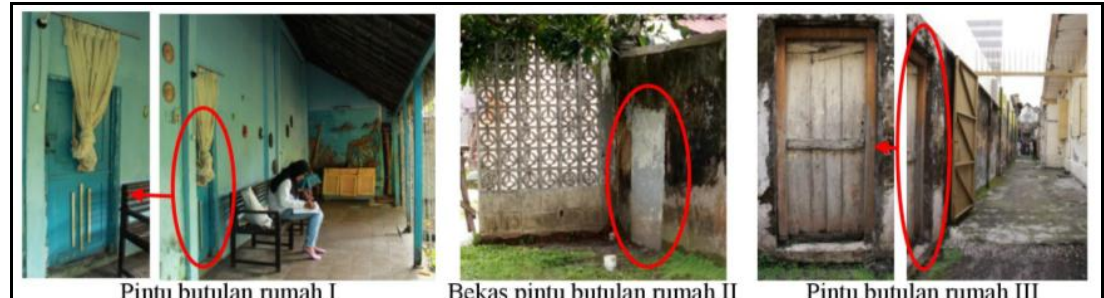

Lampiran 5. Pintu butulan menghubungkan ke rumah tetangga, sesuai karakter kekeluargaan orang Yaman,

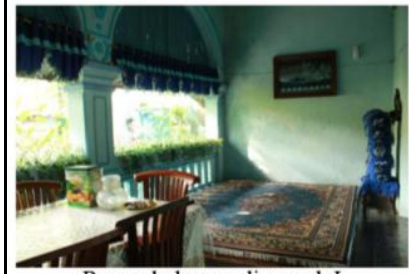

Ruang keluarga di rumah I

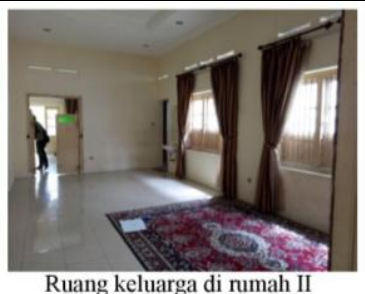

Lampiran 6. Ruang keluarga yang juga digunakan untuk menerima tamu (tabhane), sesuai dengan konsep rumah dalam peradaban Islam. Perabot berupa amben dilapis karpet dengan bantal seperti perabot di Yaman,

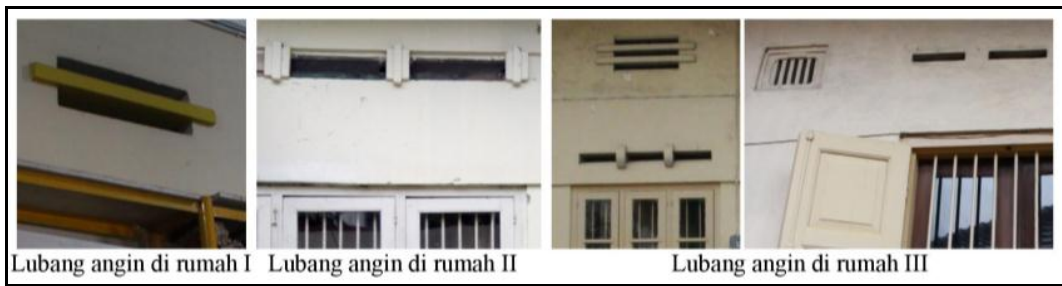

Lampiran 7. Lubang angin sebagai respon terhadap iklim tropis.

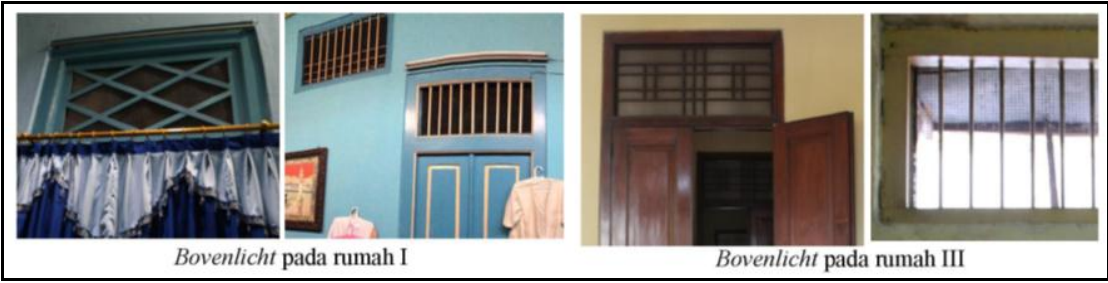

Lampiran 8. Bovenlicht berlubang yang sesuai dengan iklim tropis,

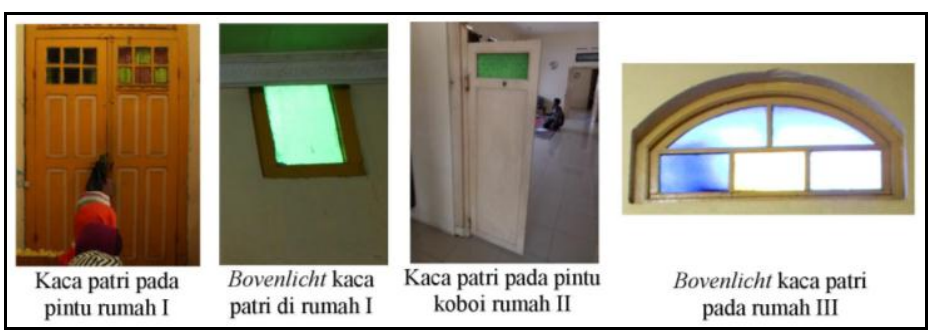

Lampiran 9. Penggunaan kaca patri pada pintu dan bovenlicht yang menjadi tren bangunan kolonial Belanda, 


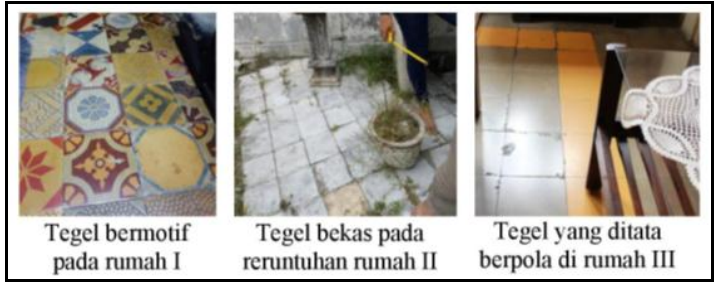

Lampiran 10. Penggunaan tegel diperkenalkan oleh Belanda dan sesuai dengan iklim tropis di Indonesia,

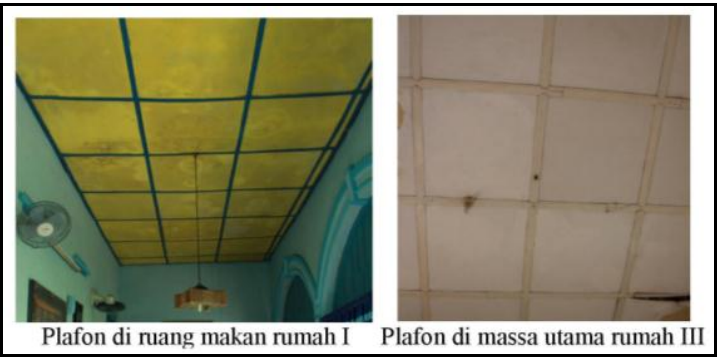

Lampiran 11. Plafon dengan balok kayu vertikal dan horizontal yang diekspos sesuai dengan karakter gaya art deco dan art nouveau yang merupakan tren dari bangunan kolonial Belanda di Indonesia.

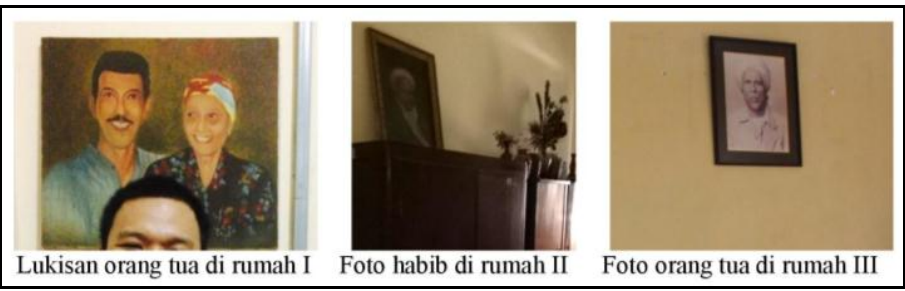

Lampiran 12. Pemasangan foto silsilah keluarga sesuai dengan kebiasaan di Yaman; pemasangan foto habib sering dilakukan oleh keturunan Arab di Indonesia;

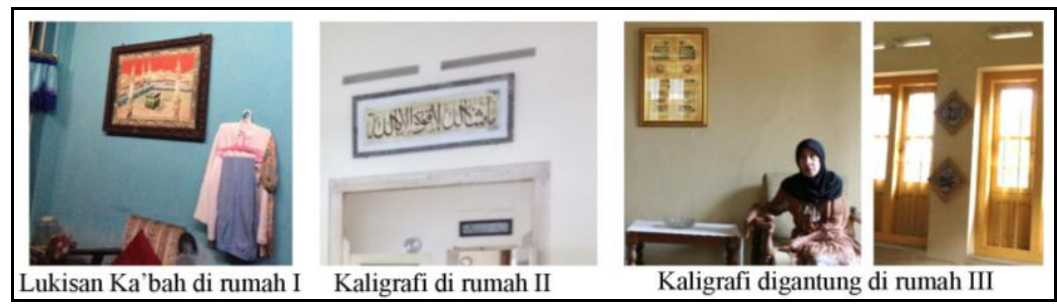

Lampiran 13. Pemasangan dekorasi islami di rumah tu etnis Arab sesuai dengan prinsip Islam,

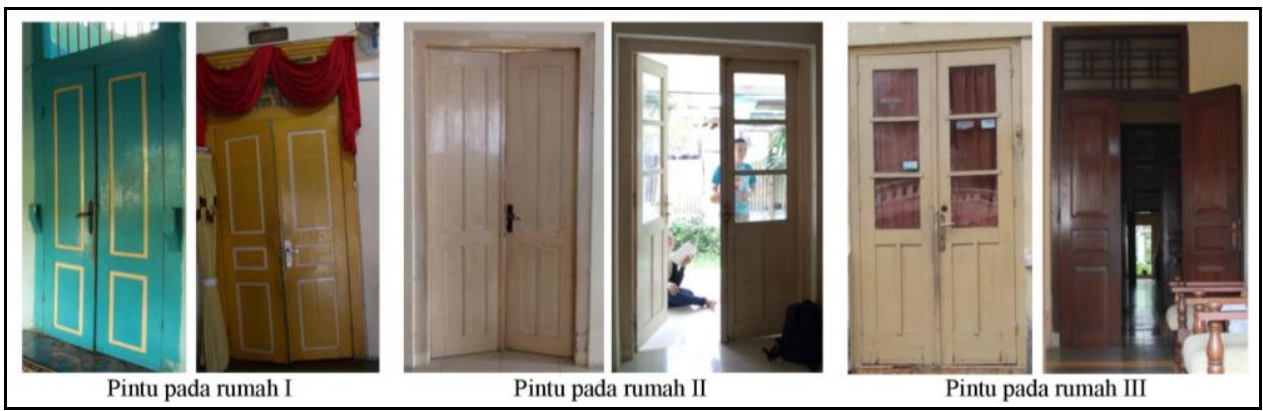

Lampiran 14. Pintu dua panel dengan motif geometris dan streamline sesuai dengan karakter gaya art deco yang menjadi tren bangunan kolonial Belanda di Indonesia, 


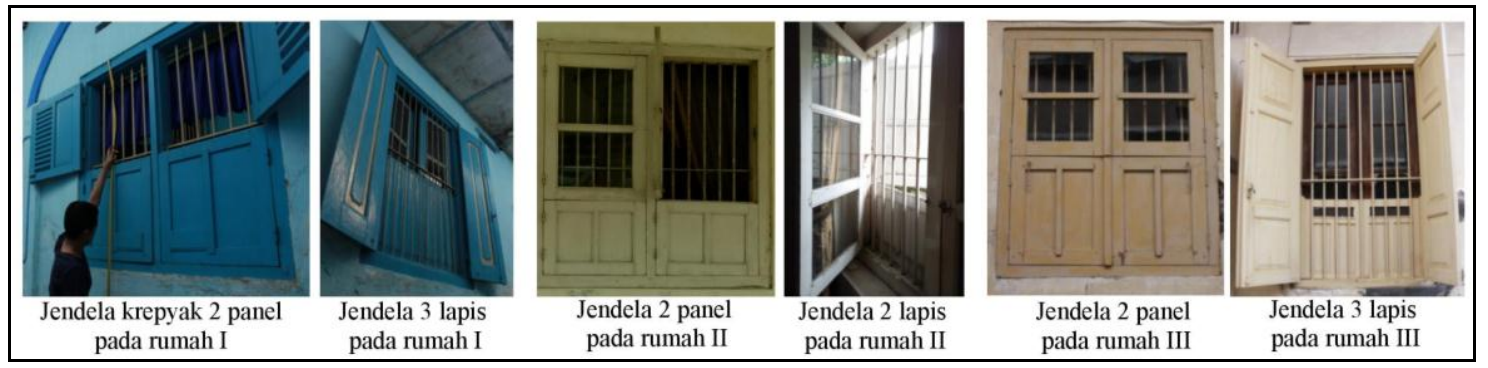

Lampiran 15. Jendela dan terali besi pada rumah tua etnis Arab dengan pengaruh arsitektur kolonial Belanda, tren lokal, dan penyesuaian iklim tropis Indonesia,

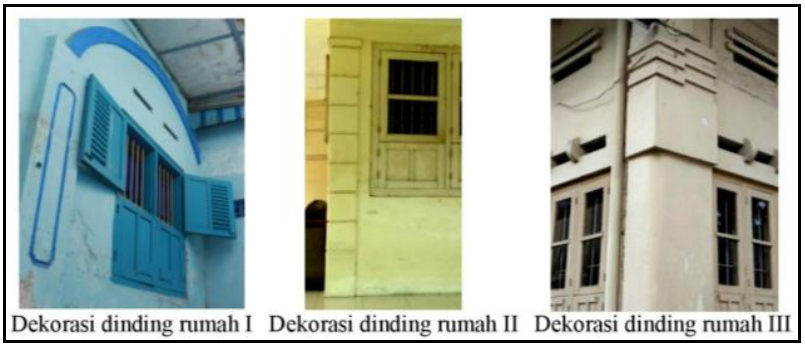

Lampiran 16. Dekorasi dinding eksterior dengan pola streamline dan geometris sesuai dengan karakter gaya art deco; warna dinding pastel terang sesuai dengan arsitektur tropis dan karakter gaya art nouveau ,

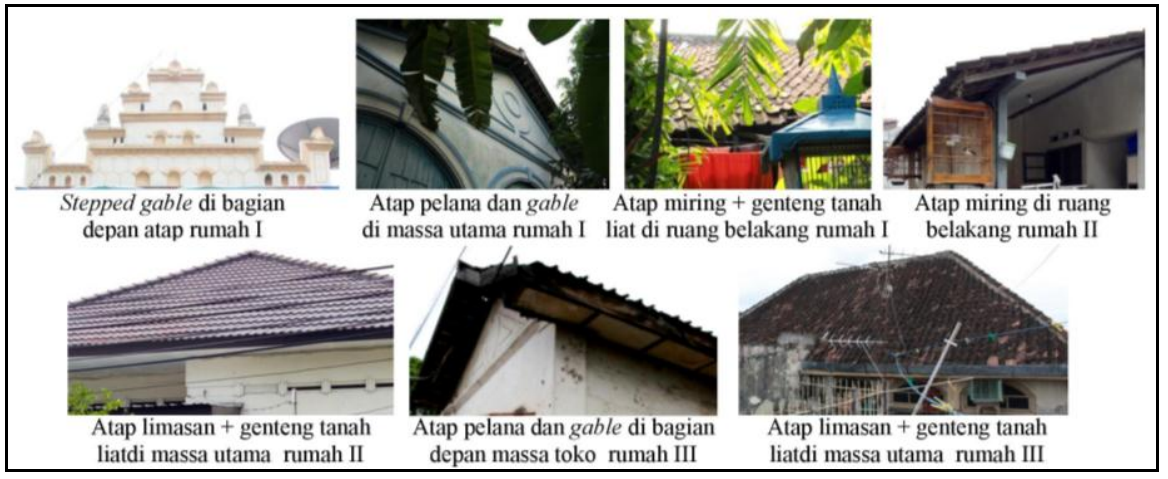

Lampiran 17. Penggunaan bentuk atap miring, gavel/gable, genteng tanah liat, dan teritis pada rumah tua etnis Arab dengan pengaruh arsitektur kolonial Belanda dan penyesuaian iklim tropis Indonesia,

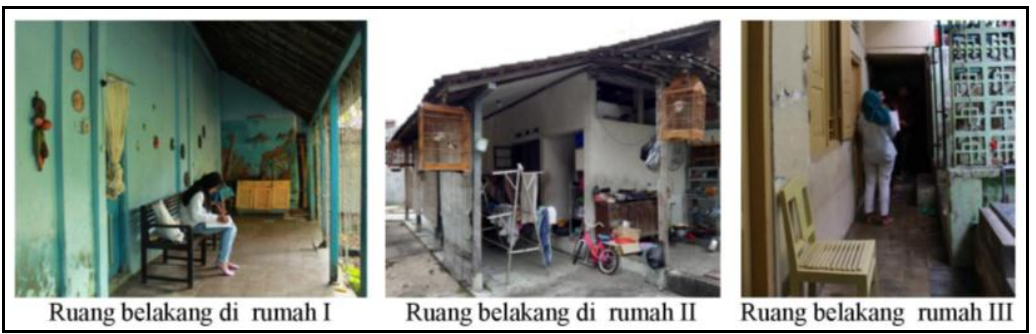

Lampiran 18. Tampilan ruang belakang dengan atap miring, selasar, dan kolom kayu serupa dengan arsitektur vernakular di Jawa dan sesuai dengan iklim tropis, 